\title{
On the Reliability (Remagnetization?) of Paleomagnetic Poles Obtained from Permo-Silurian Rocks from Oaxaca Mexico, Belize and Guatemala: Insights from Rock Magnetic Studies
}

\author{
Jose C. Guerrero-Garcia ${ }^{1}$, Emilio Herrero-Bervera ${ }^{2}$ \\ ${ }^{1}$ Instituto de Geologia UNAM, Ciudad Universitaria, Mexico City, Mexico \\ ${ }^{2}$ Paleomagnetics and Petrofabrics Laboratory, SOEST-Hawaii Institute of Geophysics and Planetology, \\ University of Hawaii at Manoa, Honolulu, USA \\ Email: herrero@soest.hawaii.edu
}

Received January 6, 2012; revised February 29, 2012; accepted March 31, 2012

\begin{abstract}
In the reconstruction of past movements of tectonic plates, the determination of reliable paleomagnetic poles is of utmost importance. To achieve accurate results, a full knowledge of the rock magnetic properties of the samples is required particularly for Curie point, for grain-size analyses in addition to thermal and alternating field (a.f.) demagnetization experiments. We present the comparative results of 20 sites drilled at 3 different Paleozoic areas: The Permian rocks of the Juchatengo area in Oaxaca, Mexico; the Late Silurian ( $418 \mathrm{Ma})$ Mountain Pine Ridge Granite, the Hummingbird Granite in Belize, and the Early Leonardian Chochal Limestone in Guatemala. The samples of all 20 sites were subjected to a.f. and thermal demagnetization in 16 steps from NRM to $100 \mathrm{mT}$, the thermally demagnetized samples were cleaned in 15 increasing temperature steps from NRM up to $675^{\circ} \mathrm{C}$. Principal component analysis was applied to the samples in order to obtain their respective mean directions. Saturation Isothermal Remanent Magnetization (SIRM), hysteresis loops, and coercivity experiments performed indicate that about $90 \%$ of the samples were characterized by Multi-Domain (MD) grain sizes and the rest were in the Pseudo-Single Domain (PSD) range of the Day diagram. Curie point determinations results ranged from $190^{\circ} \mathrm{C}$ to $660^{\circ} \mathrm{C}$, indicating the presence of titanomagnetites as well as hematite. In the Juchatengo area reliable poles were obtained from 3 sites, in Belize 3 sites and only 2 sites of the Permian Chochal Formation, Guatemala yielded coherent and useful results. All the "reliable" paleopoles obtained do not agree with the APWP of North America.
\end{abstract}

Keywords: Paleomagnetism; Remagnetization Granites; Dike; Limestones

\section{Introduction}

In the quest for precise and reliable results to be applied in the reconstruction of past movements of tectonic plates, we have performed a number of rock magnetic tests to discriminate between suitable and unsuitable rocks ranging in age between Carboniferous to Triassic units from Guatemala, Oaxaca and Belize. The studied rocks are mainly limestones, granites and metamorphosed basalts.

One of the problems encountered with most of the rocks of this study is the low magnetic stability of them to properly conduct directional analyses and to calculate their respective paleomagnetic poles, this problem is directly related to the magnetic grain sizes and their complex magnetic mineralogy. In order to discriminate the "good" versus the "bad" specimens is necessary to con- duct more detailed rock magnetic tests in addition to the common alternating field (a.f.) and thermal demagnetization experiments. The experiments proposed to characterize and determine the magnetic properties of the samples are Saturation Isothermal Remanent Magnetization (SIRM), hysteresis analyses, back-field and Curie point determinations.

In our present study we have analyzed 20 sites from the geographic areas mentioned above that after the experiments performed on them we ended up with only 8 sites that yielded reliable, coherent and meaningful results.

The process of doing extra rock magnetic experiments to characterize the magnetic properties of the sampled sites in addition to a.f. and thermal demagnetization is the purpose of this study in order to determine which are 
the most reliable and the only sites useful for further tectonic interpretations.

\section{Sampling Sites}

We sampled 20 sites distributed at three different Paleozoic areas. At Belize (Figures 1 and 2(a), e.g. [1-4], eight sites were sampled in the Maya mountain region: 3 sites in the Late Silurian (418+/-3.6 Ma) Mountain Pine Ridge Granite, 3 sites in the Late Silurian (410 - $420 \mathrm{Ma}$, [5]) Hummingbird Granite, and 2 sites in the sandy facies of the Santa Rosa Formation of Late Pennsylvanian through Permian age [2-4]. Farther south in Guatemala, three sites were drilled in the Permian Chochal Limestone (Figures 1 and 2(b), [6,7]). In Mexico (Figures 1 and 2(c)), Permian rocks (289 +/- $6 \mathrm{Ma}$, [8]) of the Juchatengo volcanic rocks (pillowed and massive lava flows, and pyroclastic rocks) were sampled at nine different sites.

The 20 sampling sites were drilled using a portable gasoline-powered drill. Magnetic and in some cases sun orientation methods were for the entire sample collection. The samples were spread out laterally within each drilled unit and taken with inclination angles between $10^{\circ}$ and $60^{\circ}$ away from the horizontal plane. A total of 160 samples were drilled from twenty widely separated rock units (see Figures 1 and 2).

\section{Laboratory Experiments}

\subsection{Natural Remanent Magnetization}

The remanent magnetization of the sites in question was measured with a JR5 spinner and a $7602 \mathrm{G}$ cryogenic magnetometer, both housed in the shielded room of the SOEST-HIGP Petrofabrics and Paleomagnetics Laboratory of the University of Hawaii. A minimum of 8 specimens per rock unit were stepwise demagnetized by

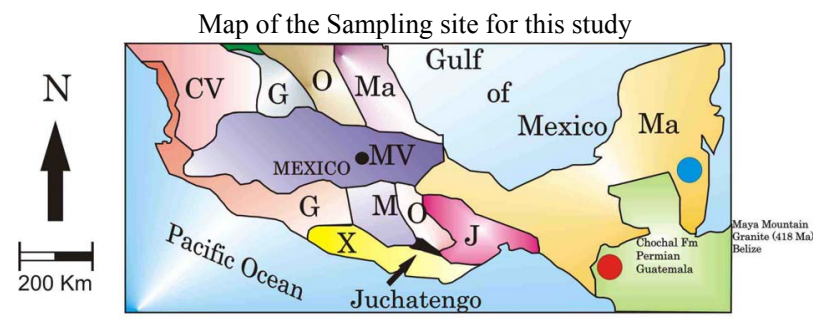

\begin{tabular}{|c|c|c|c|}
\hline \multicolumn{2}{|c|}{ Tectonostratigraphic Terranes } & \multicolumn{2}{|c|}{ Cenozoic cover } \\
\hline M & Mixteco & $\mathrm{CV}$ & Sierra Madre \\
\hline $\mathrm{Ma}$ & Maya & & Occidental \\
\hline $\mathrm{O}$ & Oaxaquia & & \\
\hline $\mathrm{G}$ & Guerrero & MV & Trans-Mexican \\
\hline $\mathrm{X}$ & Xolapa & & Volcanic Belt \\
\hline$J$ & Juarez & & \\
\hline
\end{tabular}

Figure 1. Location map of the three localities under study. Maya Mountains, Belize (Blue dot), Chochal Formation Guatemala (Red dot) and Juchatengo volcanics, Oaxaca Mexico (Black area). Taken from [8].

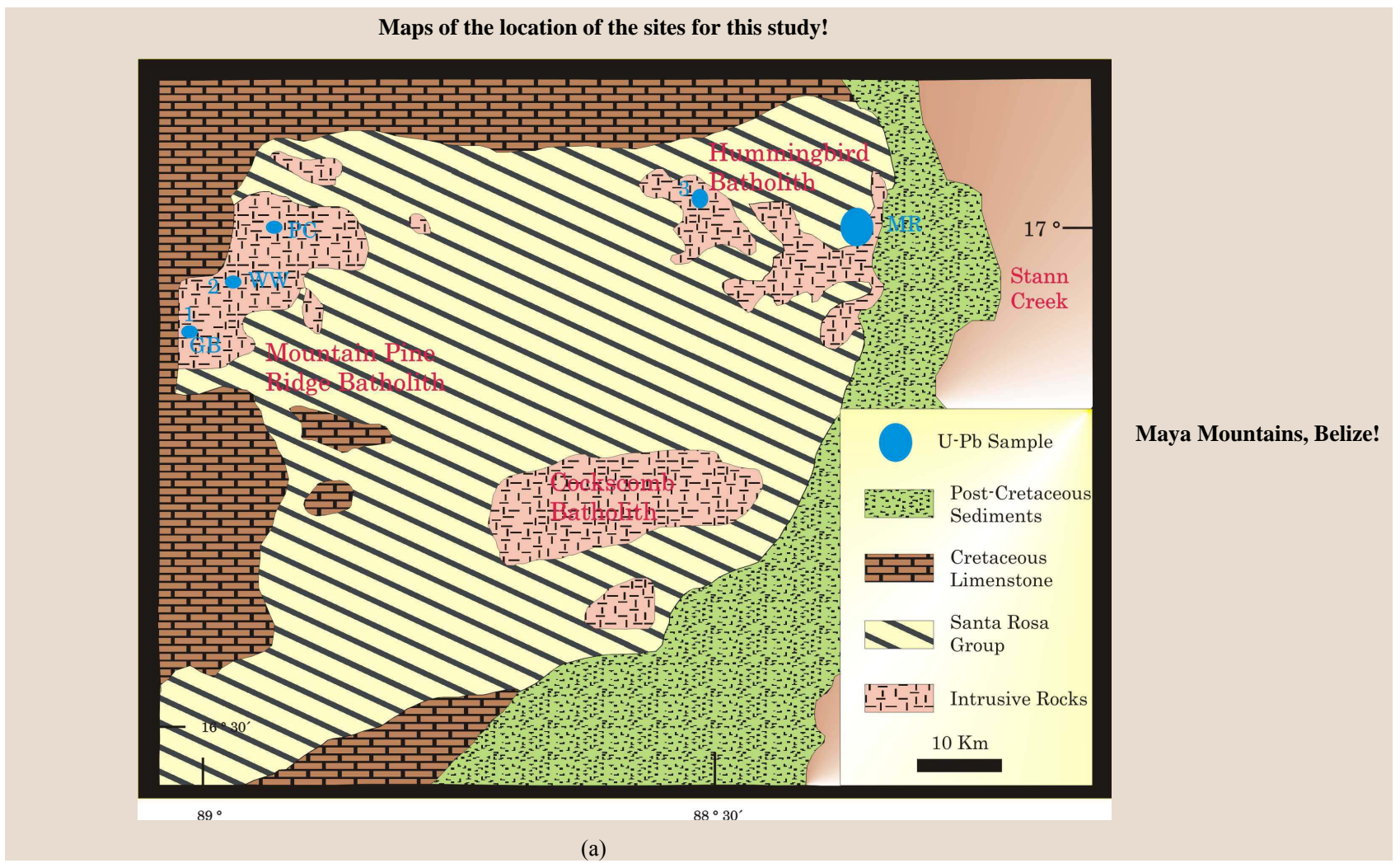


Chochal Formation, Guatemala!

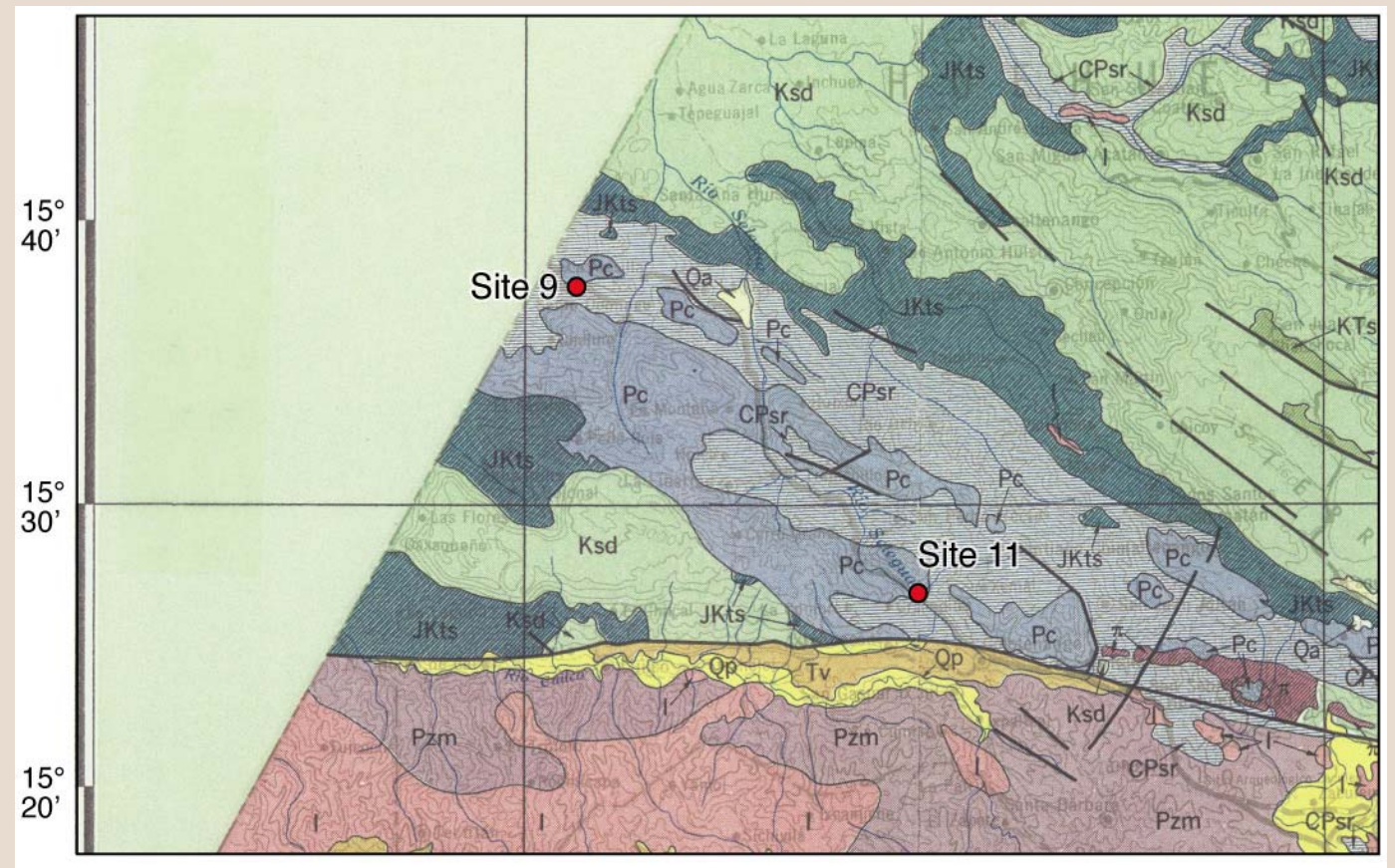

(b)

Juchatengo Oaxaca Mexico

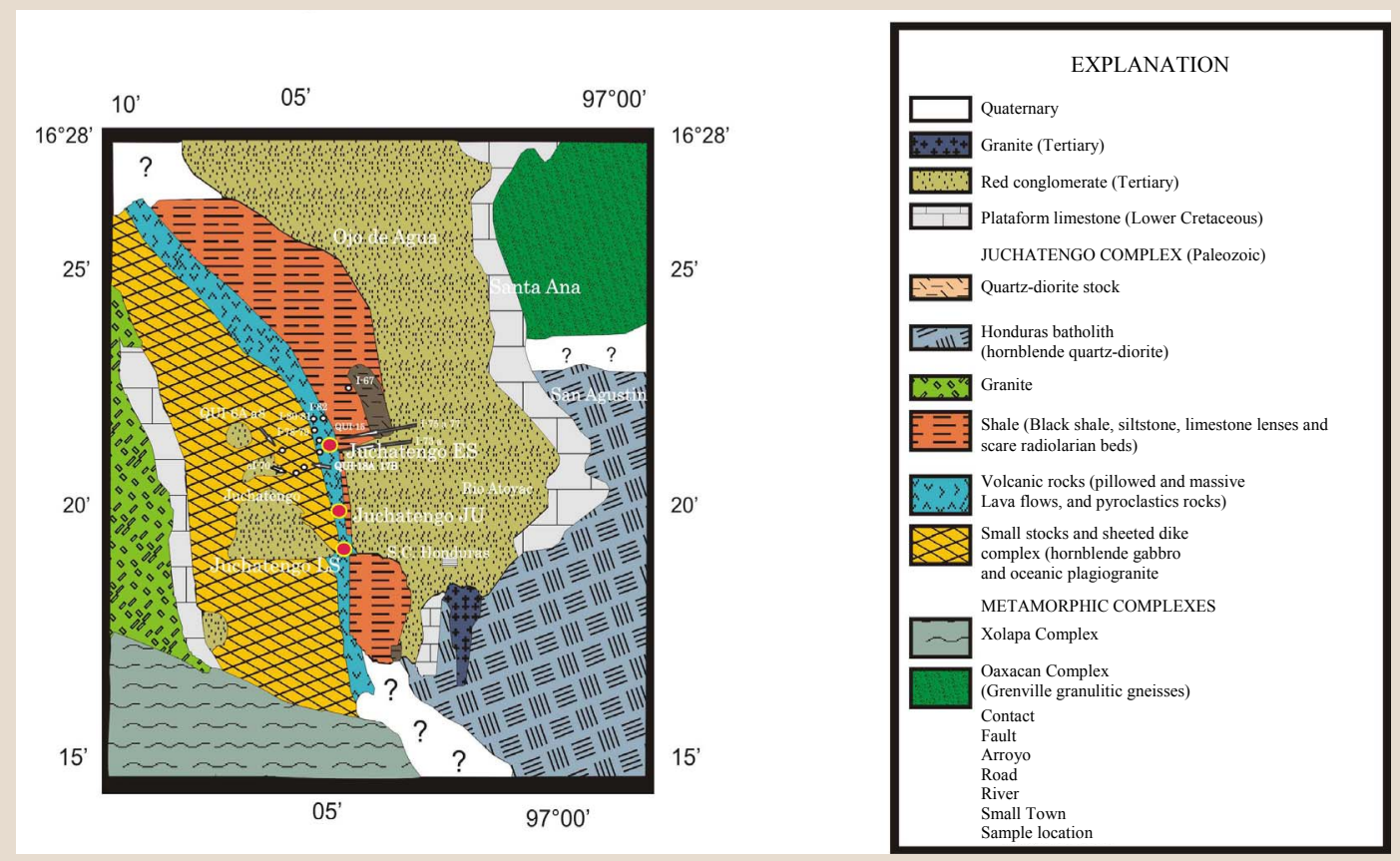

(c)

Figure 2. Maps of the three sampling localities under study. (a) Maya Mountains, three successful paleomagnetic sampling sites, Site 1, 2 and 3. Sites 1 and 2 correspond to the Guacamayo Bridge and Windroad sampling localites of [5] within the Mountain Pine Ridge Batholith. Site 3 is located within the Hummingbird Batholith. Map taken from [5]. Original map was published by [3]. The blue dots also indicate the sites with a radiometric age determination; (b) Location of paleomagnetic sites Guatemala 9 and 11 drilled in the Permian Chochal Formation, Guatemala. Map taken from [6]; (c) Sampling localites of three paleomagnetic sites drilled (JU, ES, LS) within the Lower Permian Volcanics of the Juchatengo complex, Oaxaca, southern Mexico. Modified map taken from [8]. 
alternating fields (af) from 5 to $100 \mathrm{mT}$. Few companion specimens from the same samples/cores were thermally demagnetized at 15 temperature steps from $50^{\circ} \mathrm{C}$ up to $600^{\circ} \mathrm{C}$. Therefore, a total, 200 specimens were stepwise
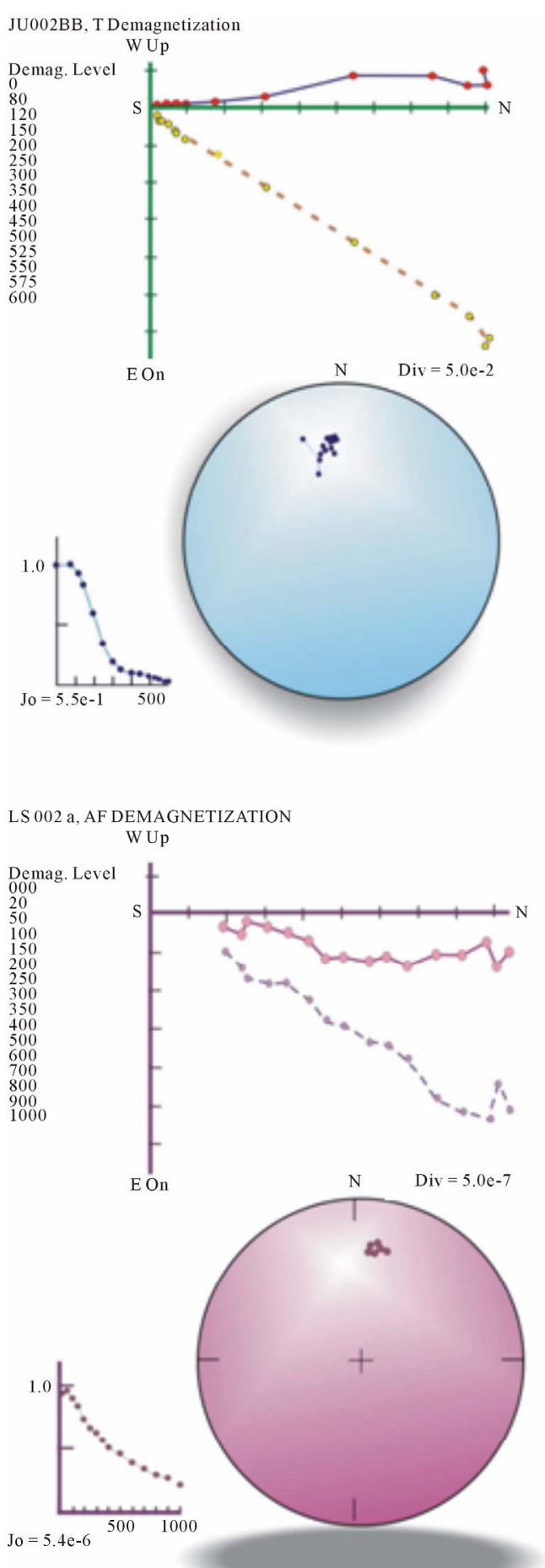

demagnetized both by temperature and a.f. for the study.

Typical demagnetization diagrams are shown in Figure 3. There is no striking difference between the overall pattern of a.f. and thermal demagnetization of all com-
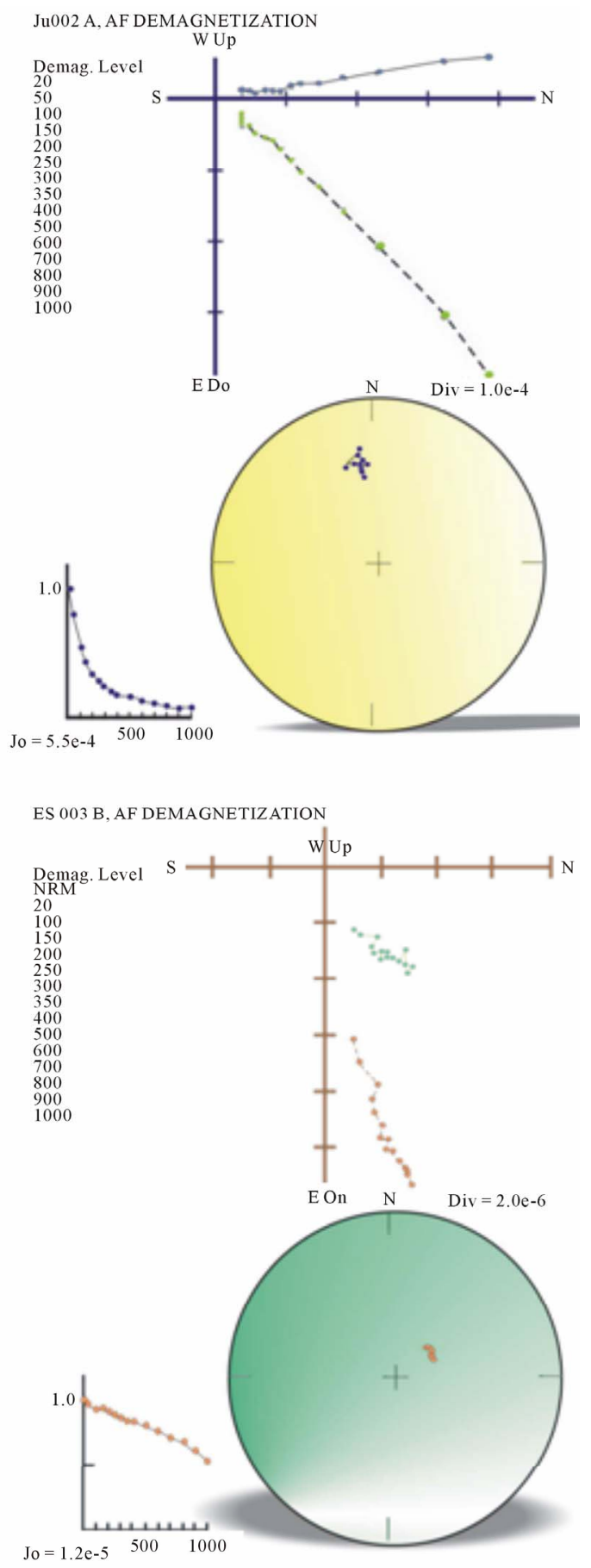

Figure 3. Typical demagnetization diagrams of normalized intensity, equal area stereograms and Zijderveld [15] vectorial plots of thermal (JU002b) and alternating field (a.f.) demagnetization (JU002a, LS002a and ES003b). Notice that sample JU002 shows the results of a.f. and temperature experiments. The a.f. demagnetization steps of 2, 50, 10 up to $100 \mathrm{mT}$ and thermal demagnetization steps of $50^{\circ} \mathrm{C}, 120^{\circ} \mathrm{C}$ up to $600^{\circ} \mathrm{C}$ were used for all samples. 
panion, although thermal demagnetization appears to be more efficient to achieve complete demagnetization. Because a.f. demagnetization appears to be more efficient during the first demagnetization steps, this resistance is likely caused by multidomain grains. The demagnetization curves confirm that magnetite carries the NRM with complete demagnetization at $580^{\circ} \mathrm{C}$ and rather soft resistance to the alternating fields applied to the specimens.

The direction of the characteristic component (ChRM) was determined using principal-component analysis for the demagnetization diagrams with a well defined component trending to the origin [9]. No direction passing away from the origin was accepted. In all cases the ChRM was defined from at least six successive directions.

The mean declination and inclination of twenty sites were determined following the procedure mentioned above. Only eight sites out of twenty studied sampling sites yielded magnetically stable, reliable and relatively coherent results. For our paleomagnetic and rock magnetic analyses we had to discard twelve sites due to lack of magnetic stability and coherency of the demagnetization results. Therefore, the study was conducted on the remaining eight sites that showed successful results in terms of their rock magnetic and paleomagnetic characteristics. We have plotted up the results of the thermal and af demagnetization of the eight remaining (three sites from Belize, two from Guatemala and three from Juchatengo, see also Figures 1 and 2) and paleomagnetically successful sites (see Figure 4) showing their mean declination and inclination directions on a stereographic projection with their respective [10] statistical parameters (see also Table 1).

\subsection{Thermomagnetic Measurements}

Studies of magnetic mineralogy were performed on at least one sample from each of the rock units under study. Thermomagnetic experiments were conducted in order to determine the Curie temperature. Twenty specimens were progressively heated from room temperature up to $700^{\circ} \mathrm{C}$ and subsequently cooled down using a Variable Field Translation Balance (VFTB) of the SOEST-HIGP Petrofabrics and Paleomagnetics Laboratory.

In Figure 5 are shown some typical diagrams of thermomagnetic experiments. A first common characteristic

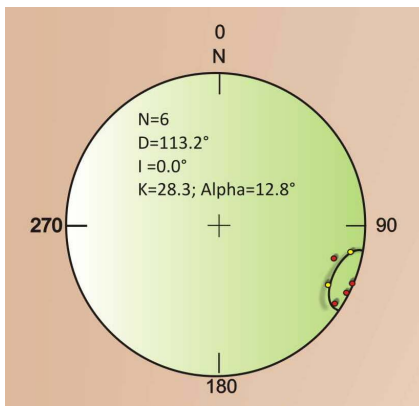

BELIZE Site 1

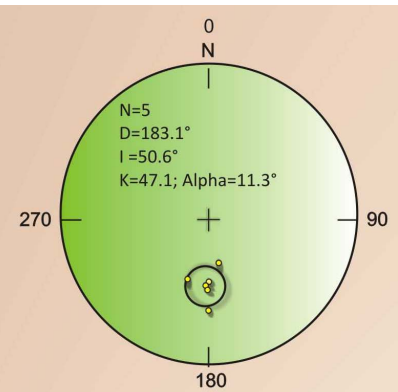

BELIZE Site 2

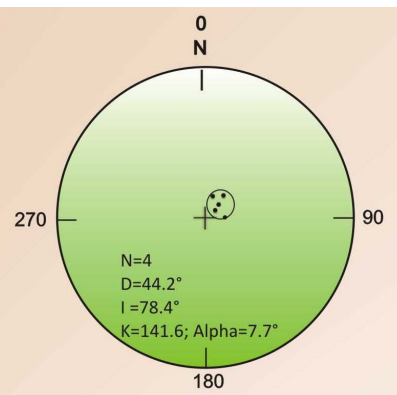

BELIZE Site 3

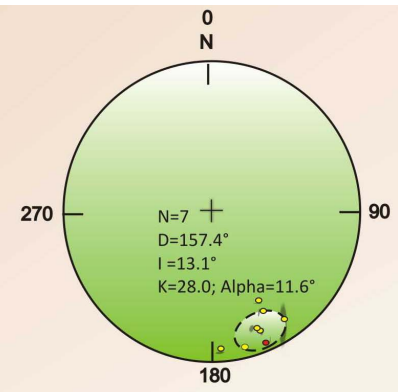

GUAT Site 9

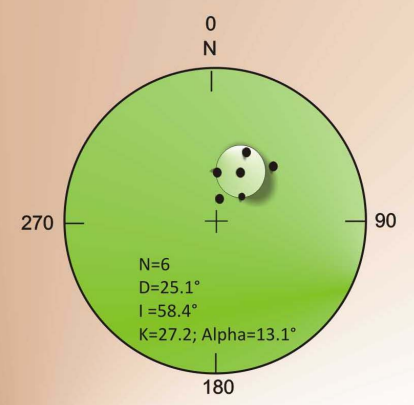

GUAT Site 11

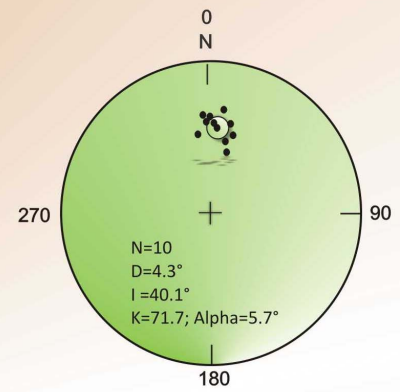

Juchatengo JU

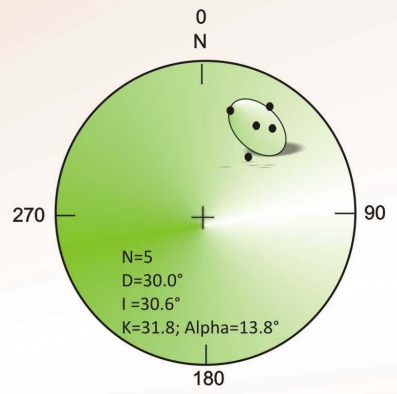

Juchatengo LS

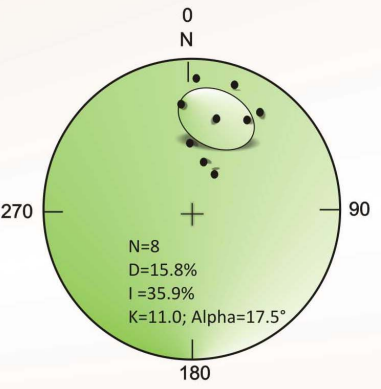

Juchatengo ES

Figure 4. Stereographic projection of the site mean directions of the eight successfully studied sites after thermal and af demagnetization. 
Table 1. Results of the Fisher statistical analyses of eight successful sites Dsecl $=$ Declination in degrees, East, of North, Inc $=$ = Inclination in degress. $\mathbf{N}=$ number of samples used, $\mathbf{R}=$ Length of the vector, Kappa = precision parameter, alpha95 = semiangle of cone of confidence for mear directions, PLON = Pole Longitude ${ }^{\circ}$ E, PLAT = Pole Latitude and (dp, $\left.\mathrm{dm}\right)$,) oval of $95 \%$ confidence about the pole position.

\begin{tabular}{|c|c|c|c|c|c|c|c|c|c|c|c|c|}
\hline Site & Coordinates & Age (Ma) & Decl & Inc. & $\mathrm{N}$ & $\mathrm{R}$ & Kappa & Alpha95 & PLON & PLAT & $\mathrm{dp}$ & $\mathrm{dm}$ \\
\hline Belize Site 1 & $270.98^{\circ} \mathrm{E} 16.82^{\circ} \mathrm{N}$ & Late Silurian $(418+/-3.6 \mathrm{Ma})$ & 113.2 & 0.6 & 6 & 5.82 & 28.3 & 12.8 & 353.6 & -22.2 & 6.4 & 12.8 \\
\hline Belize Site 2 & $270.92^{\circ} \mathrm{E} 16.91^{\circ} \mathrm{N}$ & Late Silurian $(418+/-3.6 \mathrm{Ma})$ & 183.1 & -50.6 & 5 & 4.92 & 47.1 & 11.3 & 101.4 & -75.3 & 10 & 15.2 \\
\hline Belize Site 3 & $271.49^{\circ} \mathrm{E} 17.01^{\circ} \mathrm{N}$ & Late Silurian (410 - $420 \mathrm{Ma})$ & 44.2 & 78.4 & 4 & 3.98 & 142 & 7.7 & 289.7 & 32.1 & 14 & 14.6 \\
\hline Guatemala Site 9 & $268.10^{\circ} \mathrm{E} 15.50^{\circ} \mathrm{N}$ & Early Leonardian (273 Ma) & 157.4 & -13.1 & 7 & 6.79 & 28 & 11.6 & 338.8 & -66.2 & 6 & 11.8 \\
\hline Guatemala Site 11 & $268.10^{\circ} \mathrm{E} 15.50^{\circ} \mathrm{N}$ & Early Leonardian (273 Ma) & 25.1 & 58.3 & 6 & 5.82 & 27.2 & 13.1 & 306.4 & 57.8 & 14 & 19.4 \\
\hline Juchatengo JU & $262.92^{\circ} \mathrm{E} 16.35^{\circ} \mathrm{N}$ & Permian (289 Ma) & 4.3 & 40.1 & 10 & 9.87 & 71.7 & 5.7 & 294.2 & 82.4 & 4.2 & 6.9 \\
\hline Juchatengo LS & $262.92^{\circ} \mathrm{E} 16.32^{\circ} \mathrm{N}$ & Permian (289 Ma) & 30 & 30.6 & 5 & 4.87 & 31.8 & 13.8 & 348.3 & 61.2 & 8.6 & 15.4 \\
\hline Juchatengo ES & $262.92^{\circ} \mathrm{E} 16.47^{\circ} \mathrm{N}$ & Permian (289 Ma) & 15.8 & 35.9 & 8 & 7.37 & 11 & 17.5 & 337.7 & 74.6 & 12 & 20.3 \\
\hline
\end{tabular}

to all plots is that they show a high degree of reversibility of the curves. In all these cases magnetite is identified as the unique magnetic mineral phase and the shape of the cooling curve remains identical to the heating curve. Given the absence of other visible Curie points, indicates production of additional magnetite during heating. Being aware that these diagrams are not only indicative of the magnetic grains involved in the remanence, we can anticipate that the existence of one magnetic mineral phase could have as a result some consequences on the successful behavior of the samples upon demagnetization (e.g. see Figures 3 and $\mathbf{4}$ ).

\subsection{Magnetic Hysteresis}

Magnetic hysteresis parameters were performed on small chips ( $200 \mathrm{mg})$ of rocks on VFTB apparatus. Saturation remanent magnetization $(\mathrm{Mr})$, saturation magnetization (Ms) and coercive force $(\mathrm{Hc})$ were calculated after removal of the paramagnetic contribution. The coercivity of remanence (Hcr) suggests that the NRM is carried by low-coercivity grains. The ratios of the hysteresis parameters plotted as a Day diagram $[11,12]$ in Figure 6 show that most grain sizes are scattered within the pseudo-single domain range and also within the multi-domain range. There is no obvious relation with magnetic mineralogy, and the thermomagnetic diagrams indicating almost pure magnetite are either PSD or MD in terms of their magnetic grain sizes (see Figures $\mathbf{5}$ and $\mathbf{6}$ ).

\section{Discussion}

After performing the thermal and a.f. demagnetization procedures as well as the magnetic size and thermomagnetic tests, the individual directions obtained are shown in Figure 4 for the eight sites (out of the initial twenty) that yielded reliable results from the point of view of magnetic stability. For this same reason the number of samples in each stereo-plot varies from four to ten. Even so the alpha 95 cones of confidence are quite small and leave no doubt that a truly stable remnant magnetization direction as been attained for each site. Two of the Silurian sites (418 Ma) at Belize (1 and 2) from the Mountain Pine Ridge Granite show reversed polarity while site at 3 Hummingbird Granite (210 Ma) poses normal polarity. One of the two Pemian sites at Guatemala (GUAT Site 9) exhibit inverted polarity while the other (GUAT Site 11) has normal polarity. As for the three sites in the Juchatengo area (JU, LS and ES) have normal polarity (Figure 7). With this in mind we now proceed to compare the VGP's obtained with the APWP for North America. The VGP's calculated for the three sampling sites at Belize (site 1, site 2 and site 3 ) fall way apart from each other as well as for the Silurian pole for North America. The first two come from the Mountain Pine Ridge Granite and are only seven kilometers apart. Evidently, there is no agreement at all between our paleomagnetic results and those obtained from the same sites of Steiner (2006) [13].

\section{Conclusions}

We contend that several indicators such as the conventional and routinely demagnetization experiments (i.e. a.f. and temperature) as well as magnetic granulometry and Curie point determinations yielded very important information to asses the possibility of obtaining valuable and meaningful results to conduct further paleotectonic reconstruction of the sites in question based on the experimental paleomagnetic and rock magnetic tests. Our results are as follows:

1) We have successfully isolated Characteristic Remanent Magnetization (ChRM) components of 8 sites out of 20 drilled locations by means of af and thermal de- 

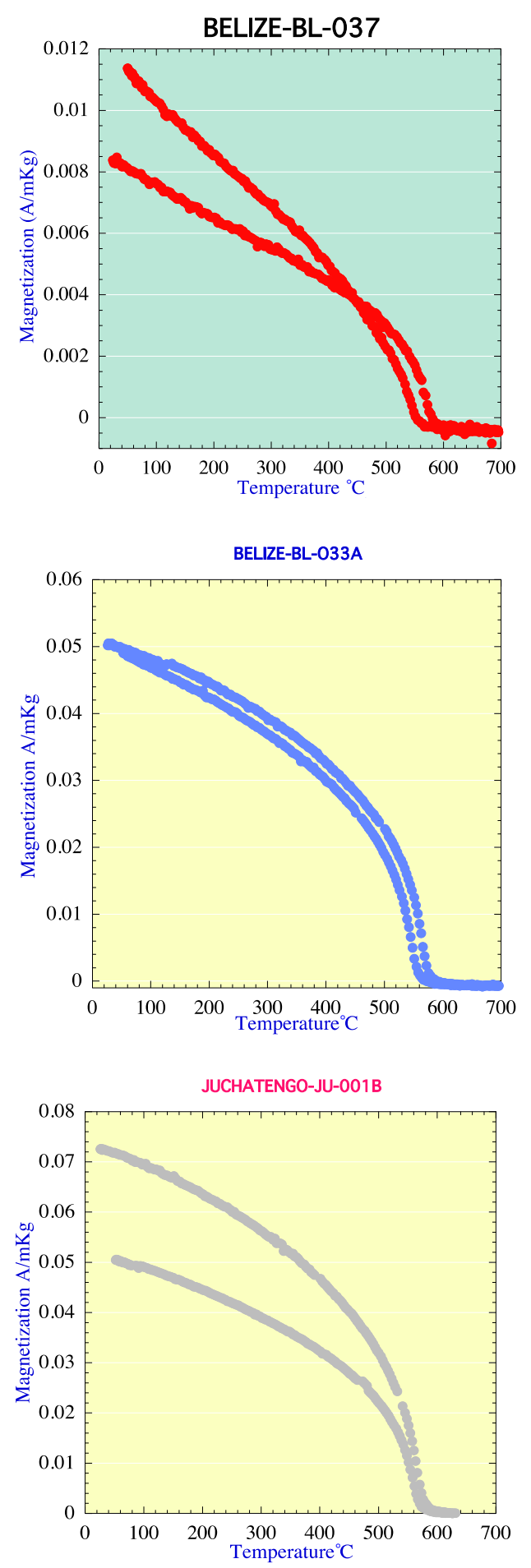

Figure 5. Thermomagnetic diagrams of typical Curie plots showing a high degree of reversibility and indicating the existence of almost pure magnetite $\left(\mathrm{Tc}=560^{\circ} \mathrm{C}-575^{\circ} \mathrm{C}\right)$. The upper part of the curves represent heating and the lower one cooling.

magnetization methods for our study.

2) Of the 8 successfully demagnetized sites only 3 of them are statistically coherent and internally consistent

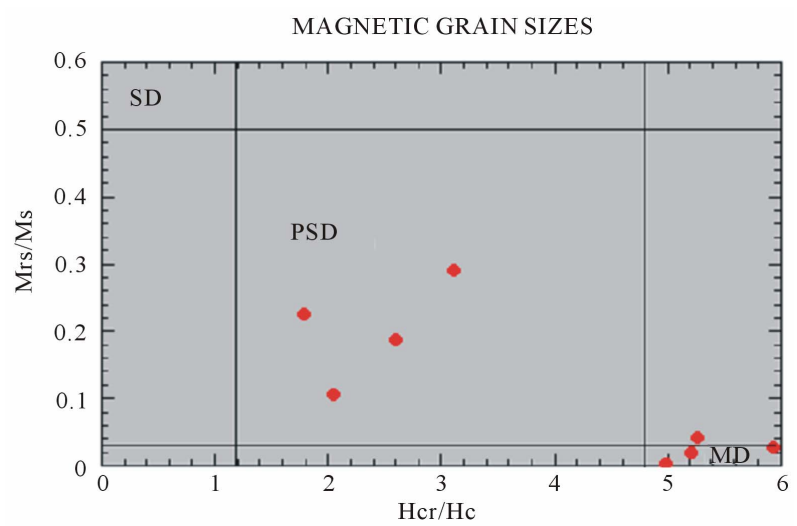

Figure 6. Plot of the hysteresis parameters, Mrs/Ms (ratio of remanent saturation moment Mrs, to saturation moment Ms) against Hcr/Hc (ratio of remanent coercive force, Hcr to coercive force $\mathrm{Hc}$ ). Notice the range of the magnetic grain sizes between Pseudo-Single (PSD) to Multi Domain (MD) for the 8 sites under study, after [11] and corrected according to [12].

from the paleomagnetic view point, (i.e. $\mathrm{N}>7$ and alpha ${ }_{95}$ less than $10^{\circ}$ for instance) see also Table 1.

3) The rock magnetic experiments performed allowed us to characterize the magnetic mineralogy of the intrusive rocks under study and we found out that the 8 "successful" sites contain almost pure magnetite, of PSD and MD magnetic grain sizes.

4) The paleomagnetic poles obtained thus far do not correlate at all with the corresponding poles of the APWP of stable North America for the Early Triassic-Late Silurian time gap e.g. [14].

These results obtained here are to a certain level expected since we have dealt with rocks such as granites, metamorphosed gabbroic dikes and black limestones that in general are not really suitable for paleomagnetic studies and that they might also have been affected by magnetomineralogical changes, drastic negative tectonic events and uncertainties related to the mode of emplacement of the granitic plutons as well as difficulties in obtaining the correct radiometric age dates of the sites in question. The bottom line of our study shows that the results obtained are very scanty and marginal to conduct further robust tectonic studies of the three sampled areas. Therefore, it is advisable that in addition to the routinely and conventional a.f. and thermal demagnetization experiments one conducts other more diagnostic rock magnetic tests in order to further characterize the magnetic properties of the material studied as is done today in modern paleomagnetism.

\section{Acknowledgements}

We gratefully acknowledge the assistance of Mr. James Lau during the laboratory phase of the project an Miss R. 


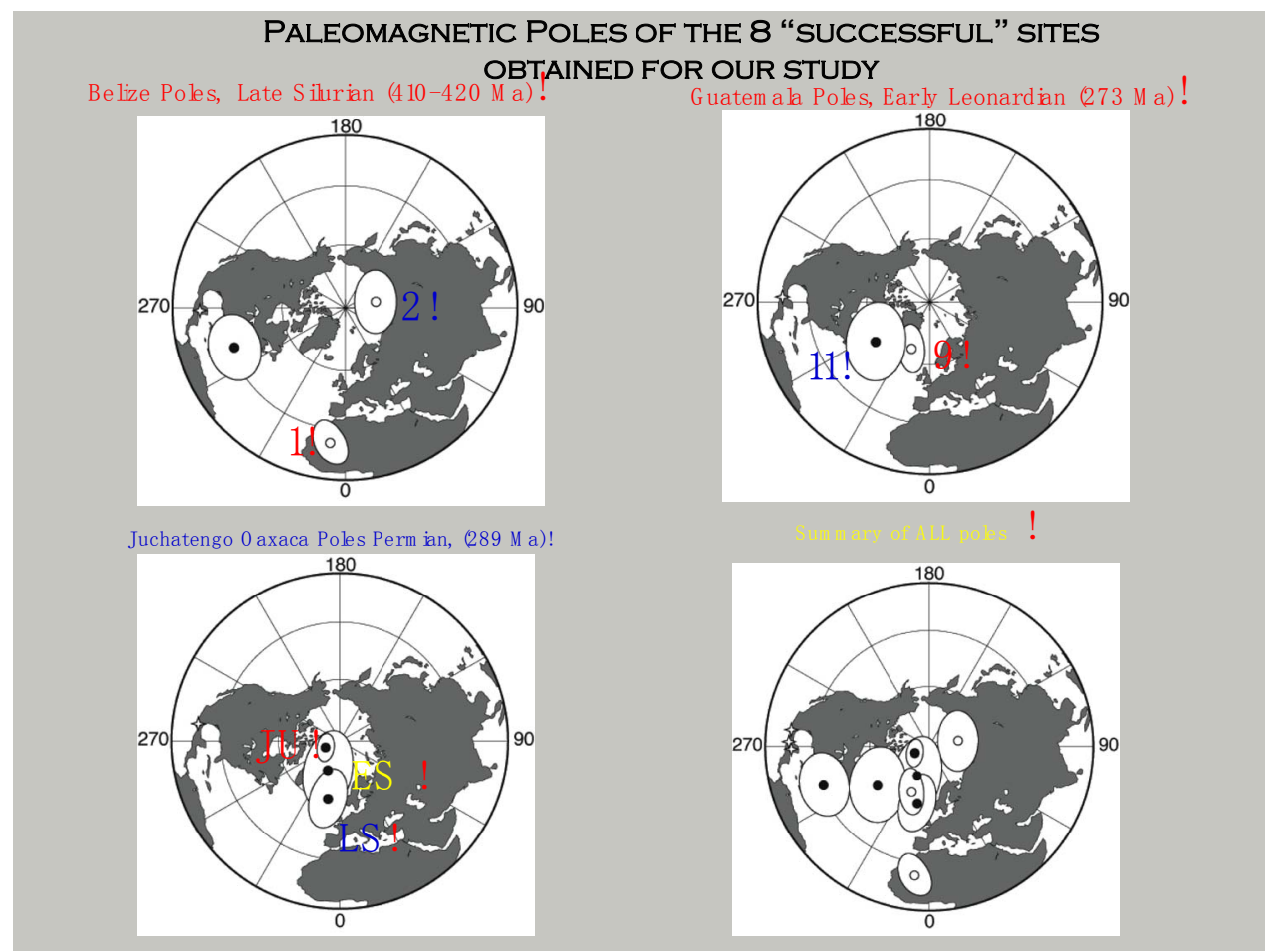

Figure 7. Paleomagnetic poles of the eight successful sites obtained for this study.

Flores for help with drafting. Funding for this research was provided by the NSF-Tectonics grant EAR90-18270 to Emilio Herrero-Bervera as well as additional financial support from SOEST-HIGP of the University of Hawaii at Manoa. Jose C. Guerrero-Garcia acknowledges the support of Instituto de Geologia, UNAM as well as DGAPA-UNAM. This is a SOEST contribution \# 8571 and HIGP \# 1923.

\section{REFERENCES}

[1] C. G. Dixon, "Geology of Southern British Honduras, with Notes on Adjacent Areas," Belize Government Printer, Belmopan, 1955, p. 85.

[2] J. H. Bateson, "New Interpretation of Geology of Maya Mountains, British Honduras," American Association of Petroleum Geologists Bulletin, Vol. 56, No. 5, 1972, pp. 956-963.

[3] J. H. Bateson and I. H. S. Hal, "Geological Map of the Maya Mountains, British Honduras," American Association of Petroleum Geologists Bulletin, Vol. 56, 1975, pp. 529-530.

[4] J. H. Bateson and I. H. S. Hall, "The Geology of the Maya Mountains-Belize," Institute of Geological Sciences Overseas Memoir 3, Her Majesty's Stationary Office, London, 1977, p. 42.

[5] M. B. Steiner and J. D. Walker, "Late Silurian Plutons in Yucatan," Journal of Geophysical Research, Vol. 101, No. 8, 1996, pp. 17727-17735. doi:10.1029/96JB00174

[6] T. H. Anderson, B. Burkart, R. E. Clemons, O. H.
Bohnenberger and D. N. Blount, "Geology of the Western Altos Cuchumatanes, Northwestern Guatemala," Geological Society of America Bulletin, Vol. 84, No. 3, 1973, pp. $805-826$.

doi:10.1130/0016-7606(1973)84<805:GOTWAC $>2.0 . \mathrm{CO}$ ;2

[7] G. Dengo, "Problems of Tectonic Relations between Central America and the Caribbean," Transactions of the Gulf Coast Association of Geological Societies, Vol. 19, 1969, pp. 311-320.

[8] J. M. Grajales-Nishimura, E. Centeno-Garcia, J. D. Keppie and J. Dostal, "Geochemistry of Paleozoic Basalts from the Juchatengo Complex of Southern Mexico: Tectonic Implications," Journal of South American Earth Sciences, Vol. 12, No. 6, 1999, pp. 537-544. doi:10.1016/S0895-9811(99)00037-1

[9] J. L. Kirschvink, "The Least-Squares Line Plane and Analysis of Paleomagnetic Data," Geophysical Journal of the Royal Astronomical Society, Vol. 45, 1980, pp. 699-718.

[10] R. A. Fisher, "Dispersion on a SPHERe," Proceedings of the Royal Society of London, Vol. A217, No. 1130, 1953, pp. 295-305.

[11] R. Day, M. D. Fuller and V. Schmidt, "Hysteresis Properties of Titanomagnetites: Grain Size and Compositional Dependence," Physics of the Earth and Planetary Interiors, Vol. 13, No. 4, 1977, pp. 260-267. doi:10.1016/0031-9201(77)90108-X

[12] D. J. Dunlop, "Theory and Application of the Day Plot (Mrs/Ms versus $\mathrm{Hcr} / \mathrm{Hc}$ ) 1. Theoretical Curves and Tests Using Titanomagnetite Data," Journal of Geophysical Research, Vol. 107, 2002, p. 22. 
doi:10.1029/2001JB000486

[13] M. J. Steiner, "Pangean Reconstruction of the Yucatan Block: Its Permian, Triassic, and Jurassic Geologic and Tectonic History," Geological Society of America, Special Paper, Vol. 393, 2006, pp. 457-480.

[14] M. W. McElhinny and P. L. McFadden, "Paleomagnetism,
Continents and Oceans," Academic Press, International Geophysics Series, San Diego, Vol. 73, 2000, p. 382.

[15] J. D. A. Zijderveld, “A.C. Demagnetization of Rocks,” In: D. W. Collinson, K. M. Creer and S. K. Runcorn, Eds., Methods in Paleomagnetism, Elsevier, New York, 1967, pp. 256-286. 